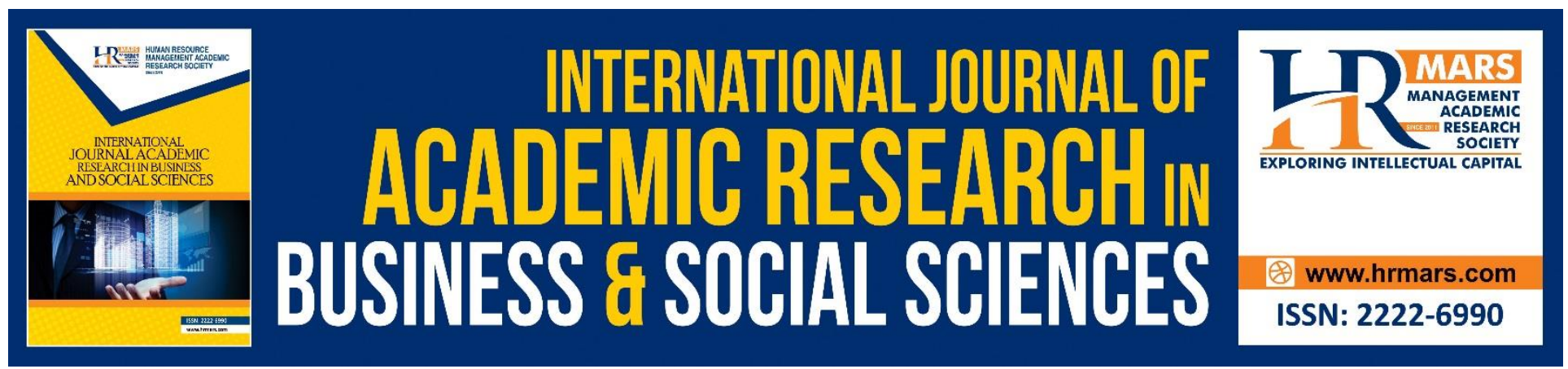

\title{
Understanding Parental Involvement Challenges from the Views of Visually Impaired Learners Parents in Pakistan
}

Shazia Malik, Umi Kalthom Abdul Manaf, Maimunah Ismail \& Nor Aniza Ahmad

To Link this Article: http://dx.doi.org/10.6007/IJARBSS/v8-i10/4796

DOI: $10.6007 /$ IJARBSS/v8-i10/4796

Received: 28 Sept 2018, Revised: 23 Oct 2018, Accepted: 29 Oct 2018

Published Online: 10 Nov 2018

In-Text Citation: (Malik, Manaf, Ismail, \& Ahmad, 2018)

To Cite this Article: Malik, S., Manaf, U. K. A., Ismail, M., \& Ahmad, N. A. (2018). Understanding Parental Involvement Challenges from the Views of Visually Impaired Learners Parents in Pakistan. International Journal of Academic Research in Business and Social Sciences, 8(10), 1020-1034.

\section{Copyright: (C) 2018 The Author(s)}

Published by Human Resource Management Academic Research Society (www.hrmars.com)

This article is published under the Creative Commons Attribution (CC BY 4.0) license. Anyone may reproduce, distribute, translate and create derivative works of this article (for both commercial and non-commercial purposes), subject to full attribution to the original publication and authors. The full terms of this license may be seen

at: http://creativecommons.org/licences/by/4.0/legalcode

Vol. 8, No. 10, 2018, Pg. 1020 - 1034

Full Terms \& Conditions of access and use can be found at http://hrmars.com/index.php/pages/detail/publication-ethics 


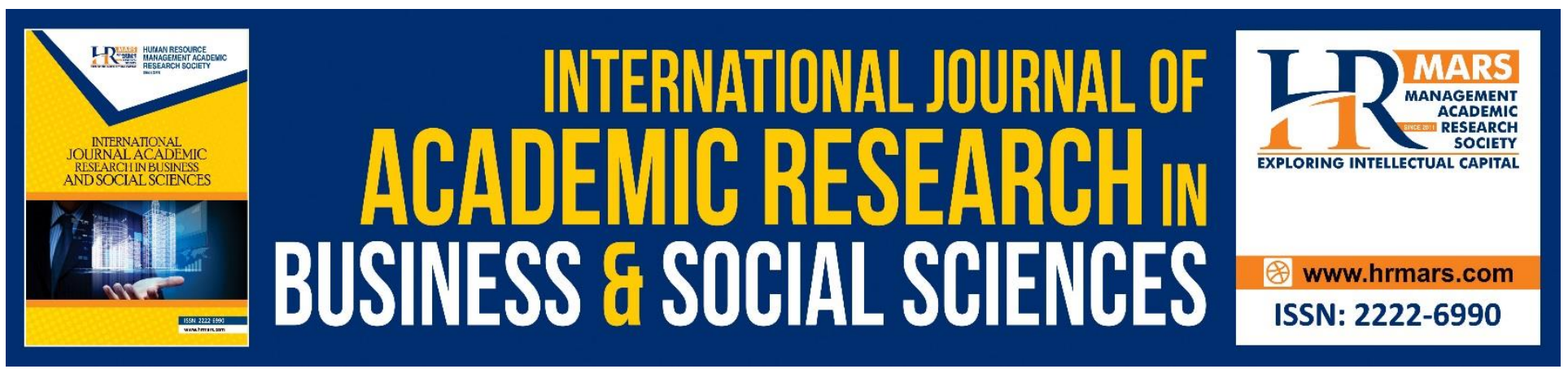

\title{
Understanding Parental Involvement Challenges from the Views of Visually Impaired Learners Parents in Pakistan
}

\author{
Shazia Malik, Umi Kalthom Abdul Manaf, Maimunah Ismail \& Nor \\ Aniza Ahmad \\ Faculty of Educational Studies, University Putra Malaysia, 43400 UPM Serdang, Selangor Darul \\ Ehsan, Malaysia
}

\begin{abstract}
Parental involvement, as one of the most widely researched and discussed issues. It has been characterized by a variety of meanings, definitions and frameworks. Such notions and definitions provide a foundation for solving parental involvement challenges in the education of the visually impaired learners. This research discusses the parental involvement challenges from the views of the parents of visually impaired learners by using a qualitative approach with semi-structured interviews of selected five parent participants from two public secondary level institutes of the visually impaired learners in Lahore, Pakistan. This paper endeavors to answer the questions like: What are the parental involvement challenges as faced by parents of visually impaired learners? What are the ways to cope with parental challenges? The findings of the paper indicate that deepen understanding of parental involvement challenges that inhibit parental involvement of the parents of visually impaired learners in their education. Five basic challenges emerged from data as the main themes, which are; being parents of visually impaired learners, no acceptance in society, less parental involvement, parental grief, and parental intentions. These parental challenges show that parents of visually impaired learners are facing difficulty in handling their disabled children and they need to cope with parental challenges with the teachers' efforts collaboratively. Finally, the suggestions are put forward to cope with parental challenges towards parental involvement in the education of their visually impaired learners.
\end{abstract}

Keywords: Parental Involvement, Parental Involvement Challenges, Visually Impaired Learners

\section{INTRODUCTION}

Worldwide, a large amount of research indicates that parental involvement mostly has a significant influence on children's academic success (Jeynes, 2011; Holloway, Yamamoto, Suzuki, \& Mindnich, 2008). In kindergarten, children's experiences and first grade place a foundation, and 
INTERNATIONAL JOURNAL OF ACADEMIC RESEARCH IN BUSINESS AND SOCIAL SCIENCES Vol. 8, No. 10, Oct. 2018, E-ISSN: 2222-6990 @ 2018 HRMARS

parents play a key role to decide their children's experiences (Turney \& Kao, 2009). Parental involvement helps to build strong parents and school partnerships with students' success. Research indicates parent's involvement in their children's education is beneficial to students and parents as well as to the educator (Sohn \& Wang, 2006). Students can increase motivation and achievement in education and improve self confidence. Parents can understand school curriculum and activities more profoundly and also can get opportunities to work closely with educators. Teachers can take advantage from parental involvement by learning family perspectives (Sohn \& Wang, 2006). Many experimental studies show strong relationships between higher student achievement and parental involvement (Wong \& Hughes, 2006).

There is a positive link between parental involvement and student competence, grades and achievement scores (Shah, 2009). However, parental involvement keeps parents socially active, such as knowing other parents, teachers, and administrators (Turney \& Kao, 2009). Moreover, where parental involvement programs are established in early childhood programs, the benefits are apparent throughout the child's school career (Bridgemohan et al., 2005). Looking for policy perspectives, parental involvement is important because one of the goals of the No Child Left Behind Act of 2001 is to increase parental involvement in elementary and secondary school (Turney \& Kao, 2009). The goal of this study is to explore parental challenges from the perspectives of the parents of visually impaired learners.

\section{LITERATURE REVIEW}

\section{Parental Involvement}

Morrison (2007) stressed that, at school the children's performance is affected by their parent involvement. Similarly, Kindiki (2009) explained that academic achievement and increased motivation can be observed when there is sufficient parental involvement in a child's education. Parental involvement is defined as an active participation and combination of commitment on the part of the parent (Gonzalez-Mena, 2011). So, parents need to be actively involved in the education of their visually impaired children to support them in their independent movement and to cope with parental challenges. Furthermore, Anyikwa and Obidike (2012) stressed that parental involvement is the parent participation and support at home and school, which impacts on the educational performance of their children. In this way, parent participation is important not only in school related activities, but they should help their visually impaired children at home.

Parental involvement contributes to visually impaired children's academic success (Anderson \& Minke, 2007). Several studies showed the connection in exploring parental involvement in educational programs and student academic achievement (Epstein, 2010). Lack of parental involvement may be resulted in less responsive to the visually impaired children's needs and creates parental challenges towards their involvement.

\section{Parental Involvement Challenges}

Parents of visually impaired learners have to face challenges like; lack of social supports, low socioeconomic status, lack of education, scored the range in terms of parenting ability as compared to parents with normal vision (Ehlers-Flint, 2000). This statement supports the notion that visual impairment alone may not account for the observed challenges of parenting with visual impairment 
(McConnell \& Llewellyn, 2002). Similarly, on more aspect that is important in creating parental challenges for the parents of visually impaired learner is the stress of their child's disability (Feldman et al., 2002). For instance, visually impairment children may experience unusual stress which can result from a history of low socioeconomic status, abuse and social isolation (Feldman et al., 1997).

There is a traditional family system in rural areas of Pakistan and only mothers are responsible for the care of children. Mothers face many socioeconomic problems during bringing up their children. A study was conducted by Iqbal, Jabeen and Maan (2014) in District Faisalabad (Punjab), Pakistan. A study was done by lqbal et, al. (2014), with identification of socioeconomic status and their relationship with the problems faced by the parents of visually impaired children. The study was quantitative in nature with 120 rural mothers respondent sample. The findings of the study revealed that main causes were mothers age, education and social income status in bringing up their disabled children. However, the results of the study showed that in rural areas of Pakistan, only mothers of children have to face many problems and take care of their children.

At times, this has resulted in psychiatric problems. Results from a program evaluation conducted by Through the Looking Glass, an agency in Berkeley, California, has suggested that $87 \%$ of parents with visual impairment were exposed to multiple stresses; history of trauma was reported in $77 \%$ of mothers of visually impaired children; $56.5 \%$ showed the evidence of dual diagnosis. Difficult early experiences are unlikely to have provided them with opportunities to learn about successful parenting. Many have been brought up in institutions or out-of-home placements such as residential housing facilities, group homes, or foster care, while others have certainly received less than optimal care at the hands of relatives. Childhood experiences as well as current social situations may be considered as significant influences on parents' Caregiving practices and beliefs (Ehlers-Flint, 2000).

However, this is not the case as in some cultures and languages; there is not even a term for disability as social differences are categorized in many various ways (Barnes, Mercer, \& Shakespeare, 2003). In many traditional societies such as the Masai and Punan Bah, the key 'disabling' condition is failure to have children; parenthood is the key to adult status. Those without children of their own, including people with physical impairments or learning difficulties are given the children of other members in their family so that they could acquire full personhood (Barnes et al., 2003). Watkins (1995) confirmed the notion that many challenges faced by parents with intellectual disabilities are a by-product of culture, rather than their intellectual disability. He claimed that when parents do struggle, it is often because of social experiences rather than their intellectual disability (Watkin, 1985).

\section{Parental Involvement Challenges towards Orientation and Mobility}

Several challenges are identified in relation to parental involvement in orientation and mobility, which are hindering parents to be involved in their children's education (Constantino, 2003; Jesse, 1986; National Parent Teacher, 2000; Patrikakou, et al, 2003). Such barriers could be included like, teacher's insufficient knowledge about cultural challenges, time, lack of information about the system of education, transport problems, less parental involvement, parental grief. Some studies identified culture a more important barrier in making less chances of parental involvement in school 
activities (Kottler \& Kottler, 2002; Noguera, 2003; Singleton \& Linton, 2006). These barriers are inhibiting parents to get involved in the orientation and mobility of their visually impaired children.

In addition to this, Constantino (2003); Kottler \& Kottler (2002), discussed that there are a limited number of parents, who are unable to understand the school requirements and also unaware about the grading system of schools. In this way, they feel depressed themselves considering disrespected during a talk with the teacher of their children. This also hindered parental involvement in orientation and mobility and creates a feeling in parents that the school personnel have no efforts in understanding their culture. Parents who are unable to speak English, feel frightened themselves in schools and they also feel themselves unable in getting proper information (Kottler \& Kottler, 2002; Muldrow, Cano, Kimmel, 1999; Noguera, 2003). Therefore, there is a need to understand the challenges that parents face to ensure a successful parental involvement in the orientation and mobility of visually impaired children for their independent movement. School administration and teachers need to play their collaborative roles to involve parents in school related activities. To sum up this discussion, all these parental involvement barriers are the biggest hindrance in creating independent in their visually impaired children's education.

\section{METHODOLOGY}

\section{Research Design}

The main purpose of this study is to understand parental challenges of parental involvement from the perspective of the parents of visually impaired. So, this study uses semi-structured interviews to answer the research questions outlined. The study also employs a qualitative research method in an attempt to describe the challenges with coping strategies that parents of visually impaired face in Pakistan. According to Willig (2001), qualitative research seeks to understand the experiences from the perspective of respondent's, and acknowledges the researcher's experience as being bias are attached parts of the process of analysis, and this leads to a better interpretation of the respondents' views. The study employs a case study method to deal with the research problem. Two government secondary levels visually impaired institutes selected in Lahore Pakistan. Case studies are the preferred approach when (why) or (how) questions are being posed, when the investigator has little control over events, and when the focus is on a contemporary phenomenon within some real-life context.

\section{Research Respondents}

Qualitative research methodology is asserted by Merriam (1988). According to Merriam (1988), qualitative research methodology focuses on quality rather than quantity, further she assumes that in qualitative research methodology, the main goals to investigate are understanding, description, discovery, and generation of hypothesis (Merriam, 1988). Some of the other factors of qualitative methodology are its setting, a sample, and the researcher as the primary instrument of data collection (Merriam, 1988). The data are collected through semi-structured interviews with using purposive sampling techniques. Merriam described that purposive sampling is based on the assumption when one wants to discover, understand, gain insight; he needs to select a sample from which he can get the most (p. 48). With this aim, the respondents were chosen purposefully by drawing on five semi-structured interviews with parents of visually impaired. They were from two 
INTERNATIONAL JOURNAL OF ACADEMIC RESEARCH IN BUSINESS AND SOCIAL SCIENCES Vol. 8, No. 10, Oct. 2018, E-ISSN: 2222-6990 @ 2018 HRMARS

secondary level public institutes of visually impaired Lahore, Pakistan. The respondents were mothers of the visually impaired with different educational level and ages. Their details are described in the following table 3.1.

Table 3.1: The profile of parent respondents $(n=5)$

\begin{tabular}{|l|l|l|l|l|l|l|}
\hline Number & Parents & Age & Education & Children & Description & Gender \\
\hline 1 & P1 & 45 & Uneducated & Two & Housewife & Mother \\
\hline 2 & P2 & 47 & B.A & One & Housewife & Mother \\
\hline 3 & P3 & 48 & M.A & One & Housewife & Mother \\
\hline 4 & P4 & 30 & Primary & One & Housewife & Mother \\
\hline 5 & P5 & 32 & M.A & Two & Housewife & Mother \\
\hline
\end{tabular}

\section{Collection of Data}

The data used in this study were generated using an interview guide developed by the researcher in the light of research questions. Semi-structured interviews were conducted with five parent respondents gave detailed description of the parental challenges towards their involvement from their prospective. The interview lasted between 30 to 40 minutes and, were made at their convenience places. The advantage of semi-structured interview are: to help and facilitate rapport and empathy that leads to gain rich and interesting data (Smith, Flowers, \& Larkin, 2009). Semistructured interviews dealt with asking respondents about parental challenges as they face in handling their visually impaired children and also help them find a way to cope with their challenge. In this study, the interview protocols provided a consistent framework; including the topics like what are the parental challenges, what are the strategies to solve parental challenges and their opinions about orientation and mobility (O\&M) to reduce their parental challenges. All interviews were recorded, allowing the researcher to take necessary notes and guide the subject into deeper areas or those areas that appeared to be superior to the current subject. Once all the interviews were conducted, the researcher started to hear the recordings and reviewing the notes to find what main themes emerged.

\section{Analysis of Data}

Qualitative data analysis is one of the feature that begins from the very start of research project prior to data collection (Berg, 2007). The qualitative data analysis process begins with the early phases of data collection. Coding and memo writing is the most important techniques for qualitative data analysis. In the present study, the interviews were recorded, transcribed verbatim, coded and analyzed according to the emerged themes. In qualitative data, coding process involved organization of themes with data reduction; making a link between themes to reach a possible conclusion. Finally, to ensure the validity of the study, some of the procedures were incorporated like field note and member checking (Merriam, 2009) by asking respondents for confirmation, clarification and completion. 


\section{Ethical Issues}

Ethical issues deal with the involvement of respondents voluntarily. It includes with designing of informed consent forms, procedures to provide the parents of visually impaired children with sufficient information to raise their awareness towards the potential risks and benefits of their participation in the interviews. This study follows the principles of confidentiality, such as, the respondents' information keeping with appropriately and anonymously. Parents selected with the help of head of the institutes and their permissions were obtained through informed consent forms.

\section{Finding of the Study}

This section presents the findings regarding the parental challenges of the parents of visually impaired about their involvement. This is accomplished by ideas generating and eliciting information from respondents about their understanding of parental involvement and parental challenges as they faced being parents of visually impaired. Data from semi-structured interviews were analyzed using cross case analysis methods. Parents of visually impaired in this study shared their challenges about their involvement with their own perspectives. All the respondents agreed that they are facing parental challenges as being parents of visually impaired and upon solving parental challenges their involvement can be enhanced. As a result, five major themes which emerged from the data on challenges of parental involvement are: parenting, time barriers, cultural challenges and less acceptance of these children in society. Parents interview transcripts are interpreted in a table format with their views.
a) Being parents
b) No acceptance in society
c) Less parental involvement in O\&M
d) Parental grief
e) Parental intentions

These are the themes which are explained by the parent. All themes are not discussed by all parent respondents, interpretations and discussions are presented from the themes of parent respondents. In the present study, these challenges are worthy of attention as they look to attained certain results in making the visually impaired learning effectively. In the context of the present study, parental challenges refer to those hurdles that they face in handling and supporting their visually impaired. According to their occurrence, the themes are presented.

\section{a) Being parents}

Interviews with parent respondents showed that the parents have to face some challenges as being the parents of visually impaired. Being parents of visually impaired is itself a big challenge. There are different views about parental challenges. The following are the excerpts from field data on being parents of visually impaired as a big challenge. 
INTERNATIONAL JOURNAL OF ACADEMIC RESEARCH IN BUSINESS AND SOCIAL SCIENCES

Vol. 8, No. 10, Oct. 2018, E-ISSN: 2222-6990 @ 2018 HRMARS

Table 4.1: Excerpts from field data on 'challenge as being parents'

Theme: Challenge as being parents

P1: When my two daughters were born, I wept a lot and I was much worried. It was a big challenge for me, after that I prepare myself to help my daughters. (INT1: 15.10.2016)

P2: At the age of four months, we came to know that our daughter has no sight and we get terrified as this is a big responsibility. (INT2: 16.10.2016)

P3: Doctor told us our daughter had no vision. This was our first and foremost challenge towards the disability of our daughter as it was a first case in our family. (INT3:

22.10.2016)

P4: I have two challenges, first being a mother of VIL and secondly no understanding about her studies. (INT4 P4: 24.10.2016)

P5: Our daughter was born and after some time, we came to know about her blindness. That time was very critical because it is a big challenge to be parents of a blind child. (INT5: 25.10.2016)

Source: Field Data

Parents shared their views that being a parent of a visually impaired is itself a big challenge. Upon asking the question about parental challenges, two of the mother started to weep bitterly, it was also showing their feelings and expressions that how they are worried and how they are facing some challenges. Parents also discussed that after a birth of the visually impaired, they were facing parental grief. All parents were hoping to get back the eyesight of their children, but as time passed the hopes were ended, all parents got medical check ups for their children.

The findings of the present study indicate that the parent respondents are facing different challenges in handling their visually impaired children and one of them is to be parents of such children. The parent respondents in the study revealed their descriptions about challenge as being parents. The following part presents cross case analysis on 'no acceptance in society'.

\section{b) No acceptance in Society}

No acceptance in society was the second big challenge faced by the parents of visually impaired. The excerpts from transcripts communicate the challenges as explained by the parent participants that in society, there is no acceptance for their visually impaired. Table 4.2 provides the excerpts from which the data are derived. 
INTERNATIONAL JOURNAL OF ACADEMIC RESEARCH IN BUSINESS AND SOCIAL SCIENCES

Vol. 8, No. 10, Oct. 2018, E-ISSN: 2222-6990 @ 2018 HRMARS

Table 4.2: Excerpts from field data on 'no acceptance in society'

Theme: No acceptance in society

P1: As parents of VIL, we have to face the society because in society there is less acceptance towards these disable children. (INT1: 15.10.2016)

P2: We parents cannot change the society. Whatever parents feel and face the challenges of VIL, they only can understand them. We parents are facing such type of problems and we cannot imagine that there will come any awareness in society, especially in our society. (INT2: 16.10.2016)

P4: There are no awareness and acceptance in society towards the disability and curriculum of VIL. Even I do not know braille. (INT4: 24.10.2016)

P5: I bring my daughter everywhere. In our society, now is some awareness, but there is no acceptance for VIL. People questioned me, what happened to my daughter, why she lost her eyes. Then many, many times, I disturbed with behavior of society. (INT5: 25.10.2016)

\section{Source: Field Data}

The way each parent described their views differs from one another. This challenge is seen as a second big hurdle to parent respondents provide in order to aid their challenges as they face in handling their visually impaired. In this respect, parents face difficulty in moving society. It seems that in society, there is no acceptance of such disabled and this is a big challenge to the parents visually impaired.

In comparison, P3 was noted to give the different description of the target words. She helped her daughter in O\&M. Her daughter is an expert in doing all her required tasks. She added her comments in these words: "Her father is very supportive. I never faced any problem in society. I bring my daughter to everywhere. I never left her at home". (INT3 P3: 22.10.2016)

The findings of the present study indicate that the parent respondents face many challenges in society being a parent of the visually impaired. In society, they are questioned about the lost vision of their children. Being parents is not the responsibility to provide sight to their children. They are unable to answer to society, and they feel and face, there is no acceptance in society for their disabled child. In the context of the present study, parents face many difficulties that are the challenges of parents, they face these challenges in handling their visually impaired children. The following part presents the cross case analysis on 'less parental involvement in O\&M'

\section{c) Less parental involvement in O\&M}

In the present study, the parent respondents were interviewed to discuss their challenges as they face in handling their visually impaired children. The excerpts from the interview and transcript data illustrates the views for each parent respondent. Table 4.3 provides the excerpts from which the data is derived. 
INTERNATIONAL JOURNAL OF ACADEMIC RESEARCH IN BUSINESS AND SOCIAL SCIENCES Vol. 8, No. 10, Oct. 2018, E-ISSN: 2222-6990 @ 2018 HRMARS

Table 4.3: Excerpts from field data on 'less parental involvement in O\&M'

Theme: Less parental involvement in O\&M

P1: We parents do not learn proper O\&M and we cannot attend the school on a daily basis. (INT1: 15.10.2016)

P2: With O\&M practices, parental challenges can be reduced and we parents show our involvement in O\&M. (INT2: 16.10.2016)

P3: Parents learn O\&M from school and practice more and more at home to make their children independently in the surroundings. (INT3: 22.10.2016)

P4: Parents want to help their children in the independent movement, but our involvement is not proper. INT4: 24.10.2016)

P5: We parents can see O\&M practices at school with our involvement in O\&M practices and learn O\&M. (INT5: 25.10.2016)

Source: Field Data

Interviews with parents show that parents feel that they have less involvement in O\&M and they want good O\&M for their visually impaired children. So, parents face challenges in handling their children and their independent in the environment seem a big challenge. In this way, parents feel that they should go to school and learn O\&M practice. As parents want the independent movement of their visually impaired children.

In sum, the parent respondents made sure that their involvement was less that could make less independent movement of their visually impaired children. To practice O\&M with the teachers and with parental involvement provides the effective independence to their children. For the present study, parents were noted to benefit from their own involvement in O\&M as they could learn O\&M from teachers. In the context of the present study, it could be the less parental involvement in $0 \& M$, which was seemed as a challenge for the parents. It seems necessary in reducing the parental challenges to actively involve in the O\&M practices in school. The following is the description of the parental grief and feelings of having visually impaired child and seems a challenge for parents.

\section{d) Parental Grief}

Parents in the study were interviewed to state their challenges in handling their visually impaired children. Evidences on the challenges explained by the parents for each of the parent is presented to give a clear picture of the problem. Table 4.4 provides the description of the parent respondents on parental grief. 
INTERNATIONAL JOURNAL OF ACADEMIC RESEARCH IN BUSINESS AND SOCIAL SCIENCES

Vol. 8, No. 10, Oct. 2018, E-ISSN: 2222-6990 @ 2018 HRMARS

Table 4.4: Excerpts from field data on 'parental grief'

Theme: Parental Grief

P1: When my two daughters were born without sight, I wept a lot and every time. Then I got ill. It was a big shock with facing this situation. (INT1: 15.10.2016)

P2: My daughter was at the age of four months and we know that she id blind. We get terrified and it was very terrible for us. (INT2: 16.10.2016)

P3: Our daughter is totally blind and the doctor told us that she has no back eye. And her eyes cannot be replaced. It was a big grief for us. (INT4: 22.10.2016)

P4: The doctor told us after the birth of three months, that our daughter has no retina in the back side of the eye to make a focus to see. It was a very bad news for us. We remain in a shock for some time. (INT4: 24.10.2016)

P5: My daughter is blind by birth, at her birth, we were very upset how we will face the challenges about her birth. It was a big grief for us.(INT5: 25.10.2016)

\section{Source: Field Data}

Parents were interviewed with an explanation about parental grief as parents face challenge. All the parent respondents were found to face a challenge as named parental grief with the birth of a visually impaired child. This indicates that parents faced a lot of hurdles and barriers in bringing up their visually impaired child. This also indicates to be provided what parents expect in the free movement of their children. All parents want to see their children as independent persons in society and they want to see their visually impaired children the persons to help them by themselves. This could perhaps, with the effective provision of O\&M practices to make them independent in their surroundings.

All the parents were found by facing the challenge of parental grief. They all helped and tried their best to bring the vision of their children. All parents were seen very upset at all the stages of their visually impaired children. This challenge provides with some ways to cope with this challenge to parents. This is in line with the parental challenges and with the effective provision of O\&M this parental challenge can be reduced. The following describes the cross case analysis on the theme 'parental intentions'.

\section{e) Parental Intentions}

Interviews with parents showed that they were facing challenges in handling their visually impaired children. Parents were also found with some parental intentions as being the challenge for their parenthood. This probably indicates that the parents were facing many difficulties to discuss their input about the challenges as they faced. Table 4.5 illustrates the data from each parent respondent on the related theme. 
INTERNATIONAL JOURNAL OF ACADEMIC RESEARCH IN BUSINESS AND SOCIAL SCIENCES Vol. 8, No. 10, Oct. 2018, E-ISSN: 2222-6990 @ 2018 HRMARS

Table 4.5: Excerpts from field data on 'parental intentions' Theme: Parental Intentions

P1: I face the health issues of my daughter, they do not eat properly and I face difficulty with this problem. (INT1: 15.10.2016)

P2: As a mother, I try my best to move my daughter. I want to build up her confidence, but she does not want to go outside. (INT2: 16.10.2016)

P3: I want to explain that independence needs more practices. I practice the skills to my daughter again and again and now she can do some works by herself. But in every new task, I get afraid about the movement of my daughter. (INT3: 22.10.2016)

P4: I want more courage for my VIL. I want their more confidence and good attitude. I want more attention of teachers towards the study of my child. (INT4: 24.10.2016)

P5: Our these disable children want more attention and proper time of parents. We as parents have so many responsibilities to handle our VIL. (INT5: 25.10.2016)

\section{Source: Field Data}

Parents described the challenges as they face in handling their visually impaired children. Presenting the description about challenges indicating that these challenges are big hurdles for parents in providing with confidence and independence in movement to their visually impaired children.

All excerpts from interview transcripts show that parental intentions are different, but with the disability the focus goes to one destination about the independence of all visually impaired children. The findings of this study could perhaps explain how these challenges affect the life of the parents of such children. In the present study, when all parent respondents discussed about challenges, they mentioned almost same problems to think and this aspect may enable the parents to cope with these challenges better.

In the context of the present study, the parent participants were interviewed for parental challenges as they face in handling their visually impaired children. Parents expressed their high expectations about the independence movement of their disabled children. In the context of the present study, it is important to know about the parental challenges to provide them some ways to cope with those challenges. In sum, cross case analysis reveals a variety of challenges faced by the parent respondents in handling their visually impaired children. Whenever possible as evidenced from the field data presented in the shape of interview reviews.

\section{CONCLUSION}

There are discussed major parental challenges that emerged as the main themes of this study. These challenges show that teachers' role is significant with responsibilities to overcome these parental challenges with collaboratively working with parents. Teachers and school administrators should find appropriate ways to contact parents to get them involved. McWilliam, Maxwell, and Sloper (1999) explain advocacy as guiding parents to advocate for themselves. In this respect, all parental challenges, which inhibit parental involvement for parents of visually impaired children. For parental encouragement, teachers and school administrators should arrange some collaborative meetings in 
INTERNATIONAL JOURNAL OF ACADEMIC RESEARCH IN BUSINESS AND SOCIAL SCIENCES

Vol. 8, No. 10, Oct. 2018, E-ISSN: 2222-6990 @ 2018 HRMARS

school boundaries. If teachers get in contact with parents who are not involved due to cultural challenges, teachers and school personnel can create an environment in school that is a place that nurtures parental involvement and allows all parents to feel comfortable (Ariza, 2002). All parents need support, advocacy, and guidance from teachers, no matter their parental challenges hinder them from their involvement, but they want their children to be successful at school and they are enthusiastic to involve in their visually impaired children's O\&M practices.

\section{Corresponding Author}

Shazia Malik, Faculty of Educational Studies, University Putra Malaysia, 43400 UPM Serdang, Selangor Darul Ehsan, Malaysia. Email: shazia11malik@hotmail.com

\section{References}

Ali, M. (2012). The shadow of colonialism on relations between immigrant parents and their children's teachers.Alberta Journal of Education, 53(2), 198-215.

Ames, C., Khoju, M., \& Watkins, T. (1993). Parent involvement: The relationship between school-tohome communication and parents' perceptions and beliefs. Baltimore, MD: Johns Hopkins University.

Anderson, K., \& Minke, K. (2007). Parent involvement in education: Toward an understanding of parents' decision making. The Journal of Educational Research, 100(5), 311-324.

Anyikwa, N., \& Obidike, N. (2012). Mothers' constructions of their roles in the literacy education of their children. Africa Development, 37(3), 57-67.

Ariza, E. N. (2002). Cultural considerations: immigrant parent involvement. Kappa Delta Pi Record, 38(3), 134-137.

Barnes, C., Mercer, G., \& Shakespeare, T. (2003). Exploring disability: A sociological introduction. Maiden, MA: Blackwell Publishing, Inc.

Berg, B.L. (2007). Qualitative research methods for the social sciences, (6th ed.). Boston, MA: Pearsons Education, Inc.

Bridgemohan, R., Van Wyk, N., \& Van Staden, C. (2005). Home-School communication in the early childhood development phase. Education, 126(1), 60-77.

Chan, W. (1995). The impact of the Parent-Teacher Association (PTA) on a secondary school in Hong Kong.Unpublished Dissertation University of Hong Kong.

Constantino, S. (2003). Engaging all families: Creating a positive school culture by putting research into practice. Lanham, MA: Scarecrow Education.

Curriculum for Excellence. (2010). Curriculum for excellence in action: Bringing life to learning and learning to life.

Ehlers-Flint, M. L. (2000). Perceptions of parenting and social supports of mothers with cognitive disabilities. Unpublished Dissertation, The California School of Professional Psychology, Alameda.

Espe-Scherwindt, M., \& Kerlin, S. (1990). Early intervention with parents with mental retardation: do we empower or impair? Infants and Young Children, 2, 21-28. 
INTERNATIONAL JOURNAL OF ACADEMIC RESEARCH IN BUSINESS AND SOCIAL SCIENCES

Vol. 8, No. 10, Oct. 2018, E-ISSN: 2222-6990 @ 2018 HRMARS

Epstein, J. L. (2010). School/family/community partnerships: Caring for the children we share. Phi Delta Kappan, 76, 701-712.

Feldman, M. A., Towns, F., Betel, J., Case, L., Rincover, A., \& Rubino, C. A. (1986). Parent Education Project II: Increasing stimulating interactions of developmentally handicapped mothers. Journal of Applied Behavior Analysis, 19, 23-37.

Feldman, M.A., Leger, M., Hon, B.A., \& Walton-Allen, N. (1997). Stress in mothers with intellectual disabilities. Journal of Child and Family Studies, 6 (4), 471-485.

Feldman, M. A., Towns, F., Betel, J., Case, L., Rincover, A., \& Rubino, C. A. (2002). Relationships between social support, stress and mother-child interactions in mothers with intellectual disabilities. Journal of Applied Research in Intellectual Disabilities, 15, 314-323.

Gonzalez-Mena, J. (2011). Foundations of early childhood education: Teaching children in a diverse setting. New York: McGraw-Hill.

Greenspan, S., \& Budd, K. S. (1986). Research on mentally retarded parents. In J. J.

Holloway, S. D., Yamamoto, Y., Suzuki, S., \& Mindnich, J. D. (2008). Determinants of parental involvement in early schooling: Evidence from Japan. Early Childhood Research \& Practice, 10.

Iqbal, U., Jabeen, N., \& Maan, A. A. (2014). Problems of the disabled children's mothers in rural of Faisalabad.

Jesse, D. (1986) Increasing parental involvement: A key to student achievement. Mid- Continent Research for Education and Learning.

Jeynes, W. H. (2011). Parental Involvement and Academic Success. New York: Routledge.

Kindiki, J. (2009). Effectiveness of boards of governors in curriculum implementation in secondary schools in Kenya. Educational Research and Reviews, 4 (5), 260- 266.

Kottler E.,. \& Kottler, J., (2002) Children with limited English: Teaching strategies for the regular classroom. Thousand Oaks, CA: Sage.

McConnell, D., \& Llewellyn, G. (2002). Stereotypes, parents with intellectual disability and child protection. Journal of Social Welfare and Family Law, 24 (3), 297-317.

McGaha, C. G. (2002). Development of parenting skills in individuals with an intellectual impairment: an epigenetic explanation. Disability \& Society, 77 (1), 81-91.

McWilliam, R. A., Maxwell, K. L., \& Sloper, K. M. (1999). Beyond involvement: are elementary schools ready to be family-centered? The School Psychology Review, 28(3), 378-394.

Merriam, S. B. (1998). Qualitative research \& case study applications in education. San Francisco: Jossey-Bass.

Merriam, S. B. (2009). Qualitative research: A guide to design and implementation. San Francisco: Jossey-Bass.

Morrison, G. S. (2007). Early childhood education today. Upper Saddle River, New Jersey: Pearson MerrillPrentice Hall.

Muldrow, D., Cano, R. \& Kimmel, H. (1999). Where have all the parents gone?

National Parent Teacher Association. (2000). Building Successful Partnerships: A guide for developing parents Family involvement programs. Bloomington, IN: National Educational Service.

Noguera, P. (2003). City schools, and the American dream. New York: Teacher College Press.

Patirkakou, E., Wessiberg, R., Manning, J., Redding, \& Walberg. (2003). School family Partnerships: promoting the social, emotional, and academic growth of children. Philadelphia, PA., The Mid- 
Atlantic Regional educational laboratory, 1-3.Reynolds, J. (2007). Parents' involvement in their children's learning and schools: How should their responsibilities relate to the role of the state? Bristol: Policy Press.

Reynolds, J. (2007). Parents' involvement in their children's learning and schools: How should their responsibilities relate to the role of the state? Bristol: Policy Press.

Shah, P. (2009). Motivating Participation: The symbolic effects of latino representation on parent school involvement. Social Science Quarterly, 90(1), 212-230.

Singh, N. N., Lancioni, G.E., Winton, A.S.W., Fisher, B.C., Wahler, R.G., McAleavy, K., Singh, J., \& Sabaawi, M. (2006). Mindful parenting decreases aggression, noncompliance, and self-injury in children with autism. Journal of Emotional and Behavioral Disorders, 14 (3), 169-177.

Singleton, G. \& Linton, C. (2006). Courageous conversations about race. Thousand Oaks, CA. Corwin Press.

Sohn, S., \& Wang, X. C. (2006). Immigrant parents' involvement in American schools: perspectives from Korean mothers. Early Childhood Education Journal, 34(2), 125-132.

Smith, J.A., Flowers, P. \& Larkin, M. (2009). Interpretative phenomenological analysis: theory, method and research. Los Angeles, Sage.

Turney, K., \& Kao, G. (2009). Barriers to school involvement: Are immigrant parents disadvantaged? The Journal of Educational Research, 102(4), 257-271.

Tymchuk, A., \& Andron, L. (1992). Project Parenting: Child interactional training with mothers who are mentally handicapped. Mental Handicap Research, 5, 4-31.

Walton-Allen, N. (1993). Psychological distress and parenting by mothers with mental retardation. Unpublished manuscript.

Watkins, C. (1995). Beyond status: The Americans with Disabilities Act and the parental rights of people labeled developmentally disabled or mentally retarded. California Law Review, 83, 1415-1474.

Willig, C. (2001). Introducing qualitative research in psychology: Adventures in theory and method. Buckingham: Open University Press.

Williams, B., Williams, J., \& Ullman, A. (2002). Parental Involvement in Education. London: Queen's Printer. 